\title{
Direct Access to 2,3,4,6-Tetrasubstituted Tetrahydro-2H-Pyrans via Tandem SN2'-Prins Cyclization
}

\author{
Jimena Scoccia, ${ }^{\curlywedge}$ Sixto J. Pérez, ${ }^{\dagger}$ Victoria Sinka, ${ }^{\S}$ Daniel A. Cruz, ${ }^{\dagger}$ Juan M. López-Soria,${ }^{\S}$ Israel Fernán- \\ dez, ${ }^{\neq}$Víctor S. Martín, ${ }^{\dagger}$ Pedro O. Miranda ${ }^{\S}$ Juan I. Padrón. ${ }^{\dagger} \S^{\S}$ \\ $\S$ Instituto de Productos Naturales y Agrobiología, CSIC, Francisco Sánchez 3, 38206 La Laguna, Tenerife, Spain. \\ †Instituto Universitario de Bio-Orgánica “Antonio González" (CIBICAN), "Síntesis Orgánica Sostenible, Unidad Asociada \\ al CSIC", Departamento de Química Orgánica, Universidad de La Laguna, Francisco Sánchez 2, 38206 La Laguna, Tenerife, \\ Spain. \\ F Departamento de Química Orgánica I, Facultad de Ciencias Químicas, Centro de Innovación en Química Avanzada \\ (ORFEO-CINQA), Universidad Complutense de Madrid, 28040-Madrid, Spain \\ 'Departamento de Química, Universidad Nacional del Sur, Av. Alem. 1253, 800 Bahía Blanca, Argentina. INQUISUR, \\ CONICET, Av. Alem. 1253, 800 Bahía Blanca, Argentina.
}

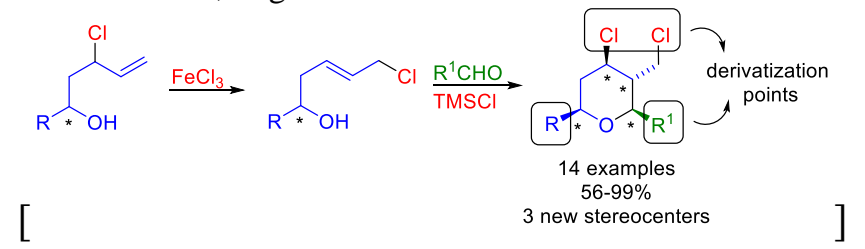

\begin{abstract}
A new direct and diastereoselective synthesis of activated 2,3,4,6-tetrasubstituted tetrahydro- $2 \mathrm{H}$-pyrans is described. In this reaction iron(III) catalyzed an $\mathrm{S}_{\mathrm{N}} 2$ '-Prins cyclization tandem process leading to the creation of three new stereocenters in one single step. These activated tetrahydro- $2 \mathrm{H}$-pyran units are easily derivatizable through $\mathrm{CuAAC}$ conjugations in order to generate multi-functionalized complex molecules. DFT calculations support the in situ $\mathrm{S}_{\mathrm{N}} 2$ ' reaction as a preliminary step in the Prins cyclization.
\end{abstract}

Functionalized tetrahydropyrans are structural motifs ubiquitous in a myriad of biologically active natural products. ${ }^{1,2}$ Several approaches to the synthesis of such moieties have been developed throughout the years with special emphasis on Prins cyclization recently. ${ }^{3-11}$ Among the plethora of substituted oxanes, 2,3,4,6-tetrasubstituted tetrahydro- $2 \mathrm{H}$-pyrans $(2,3,4,6$ THPs) constitute attractive targets since they are present in natural products, ${ }^{12,13}$ have great potential as bioisosteres of amino $\operatorname{acids}^{14}$ and are precursors of vinylcyclopropanes, ${ }^{15}$ and other species of high interest in medicinal chemistry. ${ }^{16}$ Moreover, the introduction of four different substituents in the tetrahydro pyran ring may indeed affect its three-dimensional molecular structure, and therefore, its biological activity. ${ }^{17,18}$ Also, it provides excellent opportunities toward the introduction of molecular complexity. However, despite their attractiveness as synthetic targets, there have been few reports on the synthesis of 2,3,4,6-THPs using Prins cyclization conditions, ${ }^{19-22}$ most notably due to the existence of competitive pathways that result in racemization problems and/or mixtures of undesired products. ${ }^{8,23-26}$ Additionally, the creation of new stereogenic centers, controlled by pre-existing stereochemical features, is often a challenge in acyclic molecules since it is not always easy to reduce the number of degrees of rotational freedom in a molecule. ${ }^{27}$ In the present work, we report our findings on the stereocontrolled one-pot synthesis of 2,3,4,6-THPs.

Initially, alcohol 1 was prepared in order to achieve the ironcatalyzed synthesis of disubstituted seven-membered oxacycles $\mathbf{2}$ as precursors for $\Delta^{4}-2,7$-disubstituted oxepenes $\mathbf{3}$. However, instead of the expected seven-membered ring, the observed cyclic product turned out to be the six membered oxacycle 4 (2,3,4,6-THP) adorned with four stereogenic centers, three of them generated in one single step (Figure 1). The reaction proceeded with excellent stereocontrol and with all substituents being in the equatorial position (see below, Figure 2). The presence of a primary alkyl chloride at the 3-position is of further interest since, by judicious choice of reaction conditions, it can be converted into a wide variety of functional groups, allowing us the preparation of more complicated derivatives.

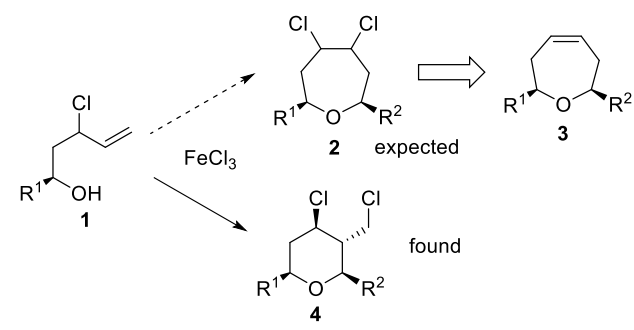

Figure 1. Initial approach for the synthesis of oxacycles.

Firstly, we carefully explored the reaction conditions in order to improve the reaction yield of the 2,3,4,6-THP 4a (Table 1). Taking into account that in previous works DCM and TMSCl have both proven to be suitable solvents and co-catalysts to carry out Prins cyclizations respectively, ${ }^{28}$ we focused on the nature of the metal source. Although stoichiometric 
amounts of $\mathrm{FeCl}_{3}$ were effective, the corresponding work-up and purification turned out to be inconvenient. Replacement of the iron halide source with organoiron or indium catalysts did not improve reaction yields. Thus, we settled on the use of 20 mol $\%$ of $\mathrm{FeCl}_{3}$ and 1.1 equiv of TMSCl as the best reaction conditions (Table 1).

Table 1. Optimization of the Reaction Conditions for the Tandem $\mathrm{S}_{\mathrm{N}}$ 2'-Prins Cyclization of 1 with Isovaleraldehyde ${ }^{\mathrm{a}}$

\begin{tabular}{|c|c|c|c|c|}
\hline entry & cat. (equiv) & $\begin{array}{l}\text { TMSCl } \\
\text { (equiv) }\end{array}$ & $t(\mathrm{~h})$ & yield $(\%)^{\mathrm{b}}$ \\
\hline 1 & $\mathrm{FeCl}_{3}(1)$ & -- & 0.5 & 80 \\
\hline 2 & $\mathrm{InCl}_{3}(1)$ & -- & 0.5 & 35 \\
\hline 3 & $\mathrm{FeCl}_{3}(0.1)$ & 1.1 & 20 & 71 \\
\hline 4 & $\mathrm{FeCl}_{3}(0.2)$ & 1.1 & 20 & 73 \\
\hline 5 & $\mathrm{Fe}(\mathrm{acac})_{3} \quad(0.1)$ & 1.1 & 20 & 48 \\
\hline 6 & $\mathrm{Fe}(\mathrm{acac})_{3}(0.2)$ & 1.1 & 20 & 50 \\
\hline 7 & $\mathrm{InCl}_{3}(0.1)$ & 1.1 & 20 & 49 \\
\hline 8 & $\mathrm{InCl}_{3}(0.2)$ & 1.1 & 20 & 57 \\
\hline 9 & $\mathrm{Fe}(\mathrm{OTf})_{3}(0.1)$ & 1.1 & 20 & 60 \\
\hline
\end{tabular}

aReaction conditions: 1 (1.0 mmol), isovaleraldehyde (1.1 mmol), [Fe], dry $\mathrm{CH}_{2} \mathrm{Cl}_{2}(0.1 \mathrm{M})$, rt, $0.5-20 \mathrm{~h}$. The stereochemistry of the THPs was assigned by GOESY experiments (see Supporting

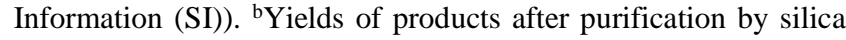
gel column chromatography.

Next, we explored the scope of the reaction by using a variety of aldehydes alongside alcohols bearing different substituents at the $\mathrm{R}^{1}$ position (Table 2). The use of either alkyl and branched aldehydes or unsaturated aldehydes gave excellent yields (Table 2, entries 1-4). Similarly, the use of aromatic aldehydes having either electron-withdrawing or electron-donating groups gave rise to the corresponding THP structures $\mathbf{4}$ in good yields (Table 2, entries 5-8). On the other hand, long alkyl chain $\mathrm{R}^{1}$-substituents also led to THPs $\mathbf{4}$ with moderate to good yields (Table 2, entries 9-13). The use of unsaturated aldehydes is important from a synthetic point of view since the alkene component allows the further functionalization of the molecule in a straightforward manner. Thus, successful dehalogenation with $\mathrm{AIBN} /(n-\mathrm{Bu})_{3} \mathrm{SnH}$ led to the corresponding 2,6-dialkyl-3methyl tetrahydro-2H-pyran (eq 1, see Supporting Information (SI)).

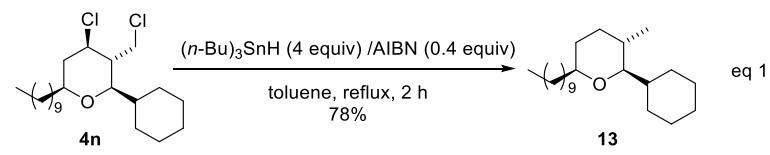

Table 2. Scope of the Tandem $S_{N} 2$ '-Prins Cyclization

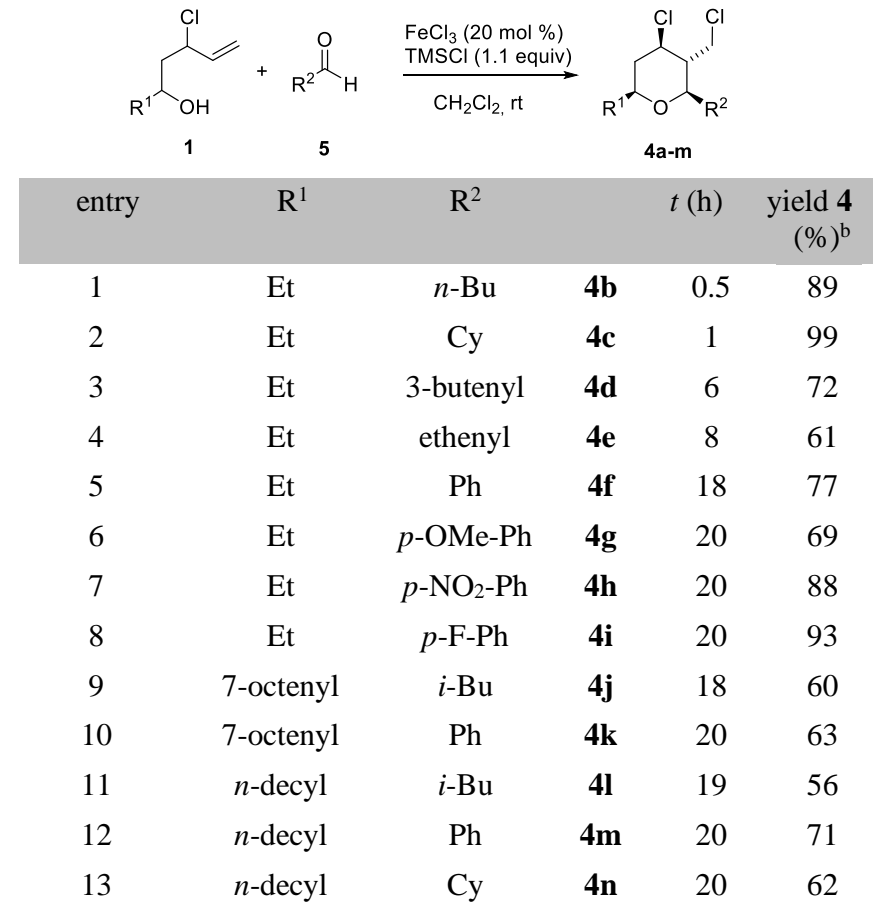

aReaction conditions: 1 (1.0 mmol), 5 (1.1 mmol), $\mathrm{FeCl}_{3}(20 \mathrm{~mol}$ $\%)$, TMSCl $(1.1 \mathrm{mmol})$ dry $\mathrm{CH}_{2} \mathrm{Cl}_{2}(0.1 \mathrm{M})$, rt. The stereochemistry of the THPs was assigned by GOESY experiments (see SI). ${ }^{\text {bY }}$ ields of products determined by ${ }^{1} \mathrm{H}$ NMR analysis with hexamethyldisilane as the internal standard.

Our next goal was to increase the molecular complexity by taking advantage of the presence of the primary alkyl chloride in THPs of structure 4. In this sense, the copper (I)-catalyzed alkyne azide cycloaddition (CuAAC) is a convenient, versatile and reliable two-step coupling procedure of two molecules that allows the generation of complexity in a quick, simple and modular fashion..$^{29-31}$ Moreover, the triazole moiety is a well-known bioisoster of the peptidic bond which enhances its biological interest. ${ }^{32}$ By way of a chemoselective $\mathrm{S}_{\mathrm{N}} 2$ displacement of the primary chloride by azide ion in quantitative yield, the subsequent $\mathrm{CuAAC}$ was achieved under microwave conditions and with no need for azide purification.

Results gathered in Table 3 clearly highlight the utility of these THP units as building blocks for the assembly of large molecules by quickly "clicking" them with small building blocks 6. Thus, the use of homopropargylic alcohol (Table 3, entry a) and phenylacetylene (Table 3, entry e) gave good yields, as well as the use of carbohydrate derivatives of glucosamine and furanose (Table 3, entries b-c). On the contrary, the use of glucal derivatives gave only moderate yields (Table 3, entry d). The ability of carbohydrate moieties to form hydrogen bonds and to provoke conformational changes in molecules, makes this combination very attractive from the pharmacological point of view. Moreover, the relative configuration of the four stereocenters in the final THP as well as its chair-like conformation with the attached triazolyl moiety were confirmed by X-Ray diffraction analysis of $\mathbf{7 e}$ (Table 3, entry e) (Figure 2). ${ }^{33}$ 
Table 3. CuAAC reaction of activated THPs

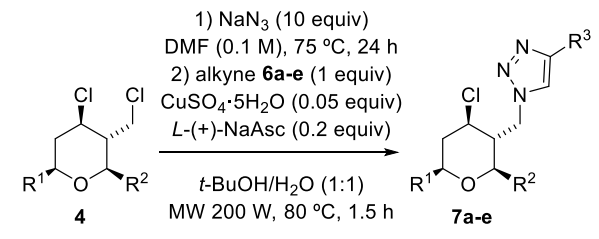

\begin{tabular}{|c|c|c|c|c|c|}
\hline entry & $\mathrm{R}^{1}$ & $\mathrm{R}^{2}$ & 6 & & $\begin{array}{r}\text { yield } 7 \\
(\%)^{2}\end{array}$ \\
\hline $\mathrm{a}$ & $\mathrm{Et}$ & $i$-Bu & & $6 a$ & 75 \\
\hline $\mathrm{b}$ & Et & $i$-Bu & & $6 b$ & 68 \\
\hline $\mathrm{c}$ & Et & $i-\mathrm{Bu}$ & & $6 c$ & 68 \\
\hline d & $n$-decyl & $i$-Bu & & 6d & 40 \\
\hline $\mathrm{e}$ & $n$-decyl & $\mathrm{Ph}$ & & $6 e$ & 80 \\
\hline
\end{tabular}

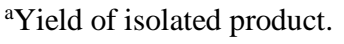

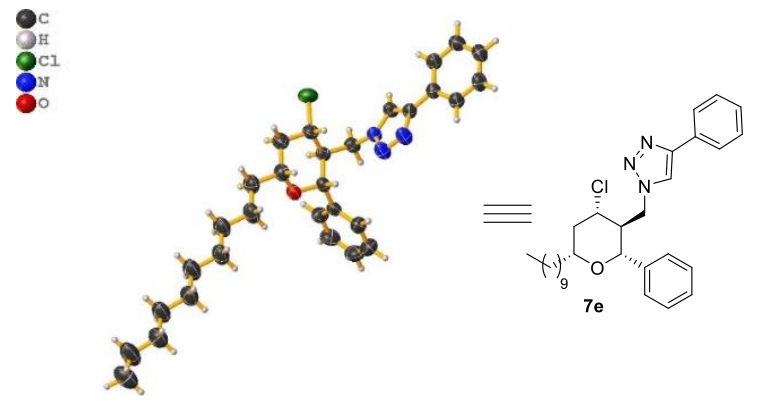

Figure 2. ORTEP plot and structure of triazole 7e.

In order to gain more insight into the reaction mechanism involved in the formation of THP $\mathbf{4 a}$, alcohol 1a was treated with substoichiometric amounts of $\mathrm{FeCl}_{3}$ ( 0.2 equiv, Scheme 2). This reaction leads to the chloro-intermediate $\mathbf{A}$, very likely via an $\mathrm{S}_{\mathrm{N}} 2$ '-type reaction. When this intermediate was reacted with isovaleraldehyde under stoichiometric amounts of $\mathrm{FeCl}_{3}$, THP 4a was obtained as the final product. Consequently, the relative syn:anti stereochemistry at the chlorine atom in the starting material is irrelevant for the outcome of the subsequent Prins-cyclization reaction.

\section{Scheme 1. Mechanistic experiments}

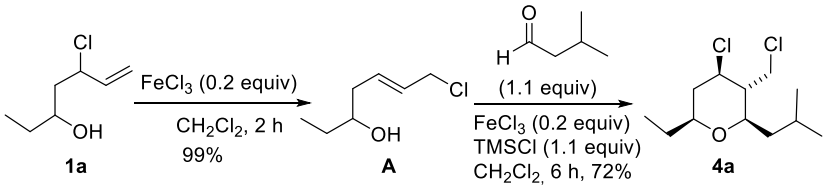

Density Functional Theory calculations at the dispersion-corrected PCM $\left(\mathrm{CH}_{2} \mathrm{Cl}_{2}\right)$-B3LYP-D3/def2-SVP level support the proposed $\mathrm{S}_{\mathrm{N}} 2$ ' mechanism for the initial iron-mediated transformation. As depicted in Figure 3, alcohol $\mathbf{1}$ is transformed, in the presence of $\mathrm{FeCl}_{3}$, into INT1 in an exothermic transformation $<$ a strong interaction between the chloride atom of $\mathbf{1}$ and the iron(III) center (the associated computed Wiberg Bond Index for this $\mathrm{Fe}-\mathrm{Cl}$ bond is 0.35 ), evolves into INT2 in a slightly endothermic process $\left(\Delta \mathrm{E}_{\mathrm{R}}=+1.9 \mathrm{kcal} / \mathrm{mol}\right)$ via transition state TS1 with an activation barrier of $+25.3 \mathrm{kcal} / \mathrm{mol}$. This saddle point is associated with the concomitant $\mathrm{C} 3-\mathrm{Cl}$ bond rupture/ $\mathrm{Cl}-\mathrm{C} 1$ bond formation mediated by transition metal fragment in an $\mathrm{S}_{\mathrm{N}} 2$ '-type reaction. INT2 is finally transformed into the observed intermediate $\mathbf{A}$ via the release of $\mathrm{FeCl}_{3}$ which acts, therefore, as a catalyst for the process. Alternatively, it can be suggested that INT1 can be transformed into the allylic cation INT3 via a $S_{N} 1$ reaction. However, the computed high endothermicity associated with the $\mathrm{FeCl}_{4}{ }^{-}$release $\left(\Delta \mathrm{E}_{\mathrm{R}}=+27.9\right.$ $\mathrm{kcal} / \mathrm{mol}$ ) together with the experimentally observed lack of formation of oxetane or dihydropyran derivatives, makes this alternative pathway highly unlikely. The subsequent exothermic Prins cyclization from the highly reactive intermediate $\mathbf{A}$ drives the complete transformation forward and leads to the observed THP 4a. ${ }^{8}$

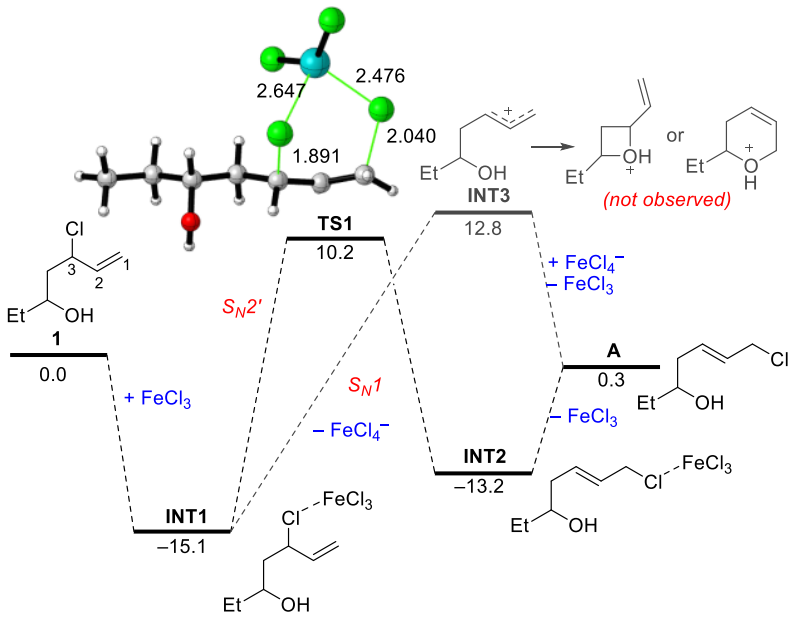

Figure 3. Computed reaction profile $\left(\mathrm{PCM}\left(\mathrm{CH}_{2} \mathrm{Cl}_{2}\right)-\mathrm{B} 3 \mathrm{LYP}\right.$ D3/def2-SVP level) for the reaction between alcohol $\mathbf{1}$ and $\mathrm{FeCl}_{3}$. Relative energies (ZPVE included) and bond distances are given in $\mathrm{kcal} / \mathrm{mol}$ and angstroms, respectively.

The transformation therefore involves a first step consisting of an $\mathrm{S}_{\mathrm{N}} 2$ ' reaction followed by a Prins cyclization in which no competitive [3,3]-sigmatropic rearrangement is detected. Hence, a stereoselective process should take place without any further racemization. To check this hypothesis, an enantioselective synthesis of conjugated-THP 12 was carried out. Starting 
from the commercially available racemic 1-epoxydodecane, a kinetic resolution was effected using Jacobsen's catalyst to obtain the epoxide $8 .^{34,35}$ The opening of this epoxide using the conditions described by Miginiac and co-workers ${ }^{36}$ led us to enantioenriched alcohol 9, with a completely defined stereocenter at the $\alpha$-position of the hydroxyl group. Since this stereocenter will be critical to the successful generation of the three new stereocenters, enantiomeric excess in the cyclization process was analyzed using 4-oxobutyl benzoate as the aldehyde 10. As expected, the overall outcome of the reaction was not affected by the possible oxonium-Cope rearrangement and consequently, no loss of the stereochemical integrity was observed in the Prins cyclization process leading to THP 11. CuAAC reaction was then fruitfully performed with the $\alpha$-glucal derivative $\mathbf{6 d}$ to afford the enantiomerically pure triazole $\mathbf{1 2}$ with an overall yield of $54 \%$.

\section{Scheme 2. Synthesis of Enantioenriched Triazole 12}

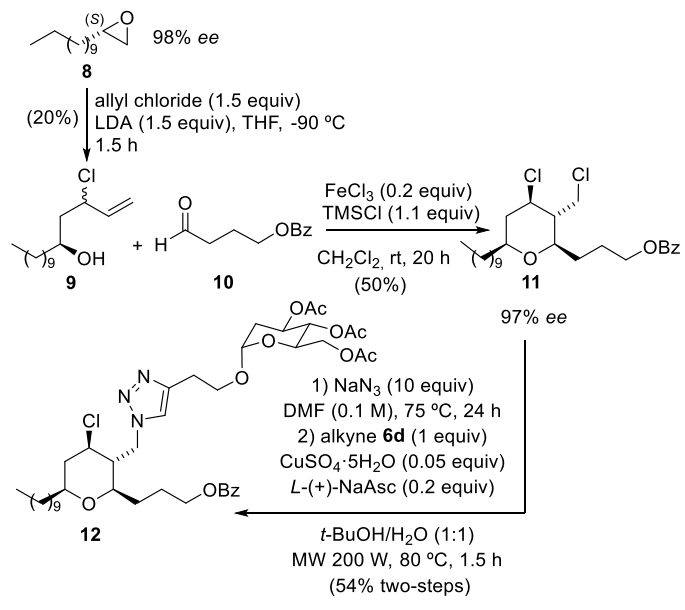

In conclusion, we have developed a new method to obtain 2,3,4,6-tetrasubstituted-tetrahydro- $2 H$-pyrans with the creation of three new stereocenters in one reaction step and in a stereoselective manner. These activated THPs are generated through a tandem $S_{N} 2$ '-Prins cyclization catalyzed by iron(III) salts. DFT calculations support the in situ $\mathrm{S}_{\mathrm{N}} 2$ ' reaction as a preliminary step of the Prins cyclization. The chlorine unit is easily derivatizable chemoselectively, via $\mathrm{S}_{\mathrm{N}} 2$ and click chemistry, which generates multi-functionalized complex molecules of interest from a biological point of view. We expect this method will be useful to the synthetic community and will change the approach to the synthesis of highly functionalized 2,3,4,6THPs.

\section{SUPPORTING INFORMATION}

Complete Experimental procedures, characterization data, copies of ${ }^{1} \mathrm{H}$ and ${ }^{13} \mathrm{C}$ NMR spectra for all new compounds, crystallographic data for $\mathbf{7 e}$, and computational details. This material is available free of charge via the Internet at http://pubs.acs.org.

\section{ACKNOWLEDGMENT}

This research was supported by the Spanish MINECO, co-financed by the European Regional Development Fund (ERDF) (CTQ201456362-C2-1-P) and MINECO-FEDER (CTQ2016-78205-P and CTQ2014-51912-REDC to I. F). D. A. C thanks the Spanish MINECO for an F.P.I fellowship. J. M. L-S thanks the Canary Island Government (ACIISI) for a pre-doctoral contract. P. O. M was supported by a Marie Curie IOF from the European Union's Seventh Framework Program FP7/2007-2013 under REA Grant Agreement No. 623155. Authors thank technician Ms. J. Dudine for her experimental assistance.

\section{REFERENCES}

1. Blunt, J. W.; Copp, B. R.; Keyzers, R. A.; Munro, M. H. G.; Prinsep, M. R. Nat. Prod. Rep. 2016, 33, 382-431.

2. Blunt, J. W.; Copp, B. R.; Keyzers, R. A.; Munro, M. H. G.; Prinsep, M. R. Nat. Prod. Rep. 2017, 34, 235-294.

3. Han, X.; Peh, G.; Floreancig, P. E. Eur. J. Org. Chem. 2013, 2013, 1193-1208.

4. Tsui, G. C.; Liu, L.; List, B. Angew. Chem. Int. Ed. 2015, 54, 7703-7706.

5. Subba Reddy, B.; Medaboina, D.; Sridhar, B.; Singarapu, K. K. J. Org. Chem. 2014, 79, 2289-2295.

6. Liu, L.; Kaib, P. S.; Tap, A.; List, B. J. Am. Chem. Soc. 2016, 138 , 10822-10825.

7. Ma, D.; Zhong, Z.; Liu, Z.; Zhang, M.; Xu, S.; Xu, D.; Song, D.; Xie, X.; She, X. Org. Lett. 2016, 18, 4328-4331.

8. Pérez, S. J.; Purino, M.; Miranda, P. O.; Martín, V. S.; Fernández, I.; Padrón, J. I. Chem. Eur. J. 2015, 21, 15211-15217.

9. Brun, E.; Bellosta, V.; Cossy, J. J. Org. Chem. 2015, 80, 86688676.

10. Lalli, C.; Van de Weghe, P. Chem. Commun. 2014, 50, 74957498.

11. Subba Reddy, B.; Venkateswarlu, A.; Borkar, P.; Yadav, J.; Sridhar, B.; Grée, R. J. Org. Chem. 2014, 79, 2716-2722.

12. Lan, Y.-H.; Chang, F.-R.; Yang, Y.-L.; Wu, Y.-C. Chem. Pharm. Bull. 2006, 54, 1040-1043.

13. Li, Y.-Y.; Wang, M.-Z.; Huang, Y.-J.; Shen, Y.-M. Mycology 2010, 1, 254-261.

14. von Roedern, E. G.; Kessler, H. Angew. Chem. Int. Ed. 1994, 33, 687-689.

15. Erickson, L. W.; Lucas, E. L.; Tollefson, E. J.; Jarvo, E. R. J. Am. Chem. Soc. 2016, 138, 14006-14011.

16. Talele, T. T. J. Med. Chem. 2016, 59, 8712-8756.

17. Andrews, I. P.; Ketcham, J. M.; Blumberg, P. M.; Kedei, N.; Lewin, N. E.; Peach, M. L.; Krische, M. J. J. Am. Chem. Soc. 2014, 136, 13209-13216.

18. Makeneni, S.; Foley, B. L.; Woods, R. J. J. Chem. Inf. Model. 2014, 54, 2744-2750.

19. Yadav, J. S.; Subba Reddy, B. V.; Narayana Kumar, G. G. K. S.; Swamy, T. Tetrahedron Lett. 2007, 48, 2205-2208.

20. Venkataiah, M.; Somaiah, P.; Reddipalli, G.; Fadnavis, N. W. Tetrahedron: Asymmetry 2009, 20, 2230-2233.

21. Biermann, U.; Lützen, A.; Metzger, J. O. Eur. J. Org. Chem. 2006, 2006, 2631-2637.

22. (a) Liu, F.; Loh, T.-P. Org. Lett. 2007, 9, 2063-2066. (b) Prins application in the Kendomycin formal synthesis: Bahnck, K. B.; Rychnovsky, S. D. J. Am. Chem. Soc. 2008, 130, 13177-13181.

23. Barry, C. S. J.; Crosby, S. R.; Harding, J. R.; Hughes, R. A.; King, C. D.; Parker, G. D.; Willis, C. L. Org. Lett. 2003, 5, 2429-2432.

24. Kataoka, K.; Ode, Y.; Matsumoto, M.; Nokami, J. Tetrahedron 2006, 62, 2471-2483.

25. Rychnovsky, S. D.; Marumoto, S.; Jaber, J. J. Org. Lett. 2001, 3 , 3815-3818.

26. Crosby, S. R.; Harding, J. R.; King, C. D.; Parker, G. D.; Willis, C. L. Org. Lett. 2002, 4, 577-580.

27. Brown, W. H.; Foote, C. S.; Iverson, B. L.; Anslyn, E. V., Organic chemistry, Cengage Learning. Inc., Belmont, CA 2008. 
28. Miranda, P. O.; Carballo, R. M.; Martín, V. S.; Padrón, J. I. Org. Lett. 2009, 11, 357-360.

29. Kolb, H. C.; Finn, M.; Sharpless, K. B. Angew.Chem. Int. Ed. 2001, 40, 2004-2021.

30. Moses, J. E.; Moorhouse, A. D. Chem. Soc. Rev. 2007, 36, 12491262.

31. Le Droumaguet, B.; Velonia, K. Chimeras. Macromol. Rapid Commun. 2008, 29, 1073-1089.

32. Oueis, E.; Jaspars, M.; Westwood, N. J.; Naismith, J. H. Angew. Chem. Int. Ed. 2016, 55, 5842-5845.

33. The absolute configuration of triazol 7e was unambiguously stablished by X-ray crystallographic analysis. CCDC 1558064 contains the supplementary crystallographic data for this compound. This data can be obtained free of charge from the cambridge Crystallographic Data Centre via www.ccdc.cam.ac.uk/data_request/cif.)

34. Savle, P. S.; Lamoreaux, M. J.; Berry, J. F.; Gandour, R. D. Tetrahedron: Asymmetry 1998, 9, 1843-1846.

35. Schaus, S. E.; Brandes, B. D.; Larrow, J. F.; Tokunaga, M.; Hansen, K. B.; Gould, A. E.; Furrow, M. E.; Jacobsen, E. N. J. Am. Chem. Soc. 2002, 124, 1307-1315.

36. Ongoka, P.; Mauzé, B.; Miginiac, L. J. Organomet. Chem. 1985, 284, 139-147. 